\title{
S- 9-7 Cystatins as Regulators of Intracellular Proteolysis
}

\author{
V.TURK
}

Department of Biochemistry, Jožef Stefan Institute, Jamova 39, 61000 Ljubljana, (Slovenia)

\section{INTRODUCTION}

Our understanding of cellular processes involving protein degradation has reached the level at which it is possible to explain with more certainty the regulation and mechanism controlling proteinase activities. It has become also evident that cellular proteolysis is a highly controlled and complex process that takes place virtually in all compartments of cells (1). Among four classes of proteinases, the aspartic, the serine, the metallo and cysteine proteinases, more recently attention has been paid to the last group of enzymes. Current evidence suggests that mammalian lysosomal cysteine cathepsins B, H, L and S are well characterized proteins (2, 3) with known primary structures $(4-6)$. Very recently, the crystal structure of human liver cathepsin $B$ has been solved by X-ray crystallography indicating that the overall folding pattern of this enzyme and the arrangement of the active-site residues are similar to the related cysteine proteinases papain and actinidin (7).

During the last decade it has also become evident that newly discovered endogenous protein inhibitors of cysteine proteinases, named cystatins, offer a new insight into the processes in which they participate $(3,8,9)$. Cystatins might protect the cells from inappropriate proteolysis and/or could be involved in the control mechanism responsible for intracellular or extracellular protein breakdown. These inhibitors are widely distributed in various tissues of mammalian and plant origin (8).

In this report we will stress briefly some of the most important features of cystatins including their primary structures, crystal structure and the mechanism of interaction with their target enzymes. 
The cystatins are tight and reversibly binding inhibitors of papainlike cysteine proteinases. They form a superfamily of sequentially homologous proteins which are on the basis of their primary structures and the presence and positions of intradomainal disulphide connections subdivided into three families, the stefins, the cystatins and the kininogens (10). The recently discovered cathelin, a protein inhibitor of cathepsin $L$, indicates that a new family of cysteine proteinases may exist (11).

The protein inhibitors of the stefin family are single chain proteins with Mr of about 11000, which lack disulphide bonds and carbohydrates (reviewed in 8 ). Whereas human stefin $A$ and rat cystatin $\alpha$ are found in various types of epithelial cells, human stefin $B$ and rat cystatin $z$ are found to be widely distributed in various organs at similar levels $(2,8)$. Stefins are stable in the neutral and alkaline $\mathrm{pH}$ range as well as heat stable. Human stefin $B$ forms disulphide-linked inactive dimers which can be converted to the inhibitory active monomer under reducing conditions. Dimeric bond formation is consistent with similar observation for rat cystatin $z$. It has been suggested that the inhibitory activity of rat cystatin $z$ can be regulated with covalent modification by forming a mixed disulphide with glutathione (reviewed in 2). In order to avoid dimer formation the mutant [ $\mathrm{Ser}^{3}$ ] stefin B was prepared and the resulting recombinant protein was prepared for determination of the crystal structure of stefin B in a complex with papain (12).

The main characteristics of the cystatin family is the presence of two disulphide bonds located towards the carboxyl terminus of the molecule. They are composed of about 115 amino acid residues with Mr of about 13000 . These proteins occur at relatively high concentrations in many biological fluids. The best known representatives of this family are chicken cystatin and human cystatin $\mathrm{C}$ (reviewed in 8, 9). Chicken cystatin also has been crystallized and its three-dimensional structure determined (13).

The kininogens known as the precursor proteins of the kinins, are also potent inhibitors of cysteine proteinases. They are single-chain proteins. Low Mr kininogen (L-kininogen) has Mr of about 68000 and is glycosilated. The kininogens are strong inhibitors of papain and cathepsin $L$ (reviewed in 8 , 9). They have been found in plasma and other secretions of mammalian species reviewed in 8 ). By sequence analysis three domains corresponding to the individual cystatin-like domains (segments) were identified. These domains may be separated after subjecting L-kininogen molecule to limited proteolysis with trpysin, chymotrypsin, elastase and other proteinases and numbered 1-3 from the N-terminus (Fig. 1). Only domain 1 was not inhibitory for cysteine 


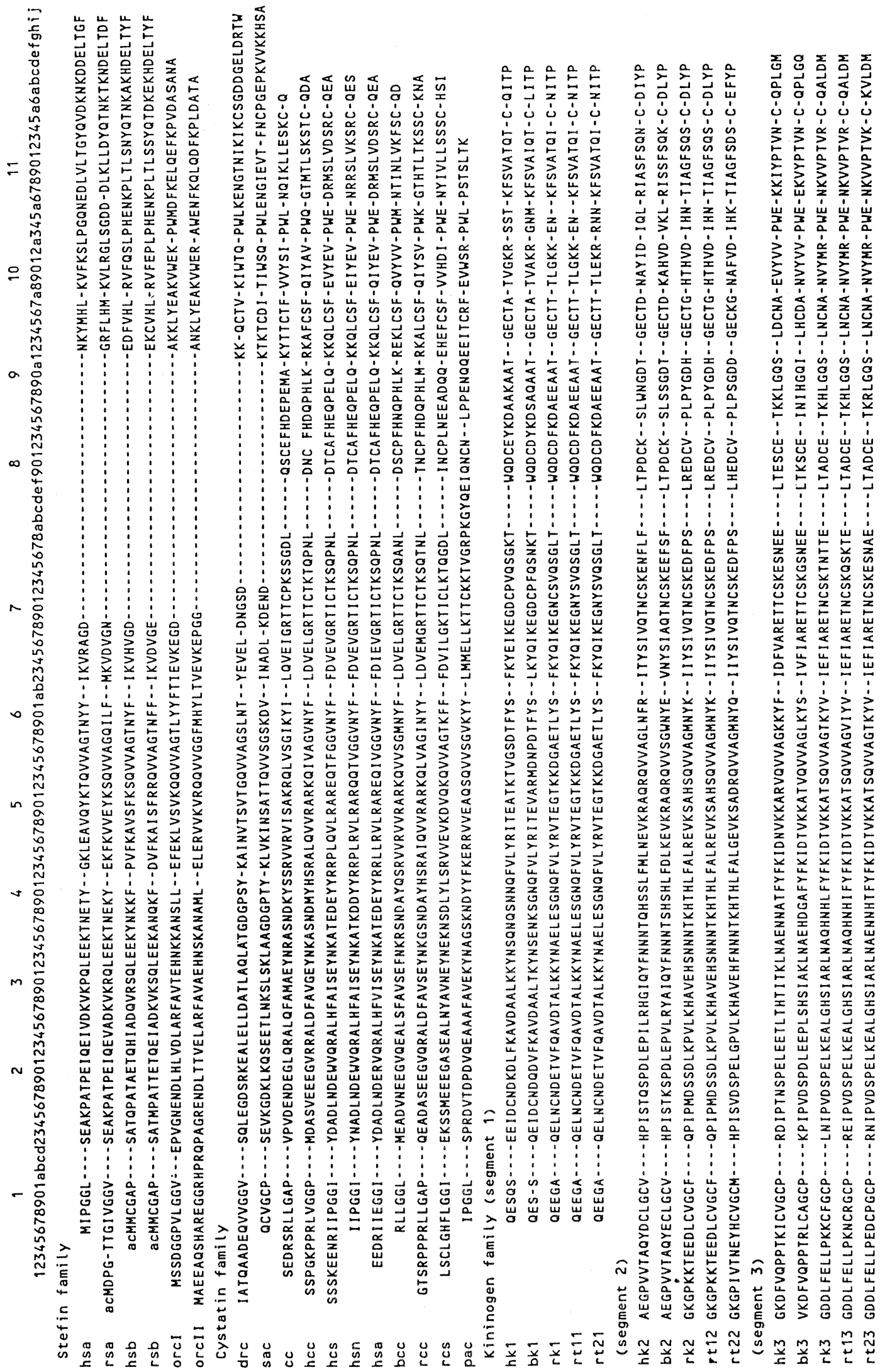


Fig. 1. Alignment of amino acid sequences of stefins, cystatin and the homologous domains of kininogens. The alignment has been prepared mainly by use of the ALIGN programme. Numbering is according to the chicken cystatin sequence using the single letter code for amino acids. Key: (hsa) human stefin $\mathrm{A}$; (rsa) rat cystatin $\alpha$; (hsb) human stefin $\mathrm{B}$; (rsb) rat cystatin $z$; (orcI) oryzacystatin I; (orcII) oryzacystatin II; (drc) Drosophila cystatin; (sac) sacrocystatin A; (hcc) human cystatin C; (cc) chicken cystatin; (rce) rat cystatin C; (rcs) rat cystatin $S$; (hcs) human cystatin $S$; (hsn) human cystatin $\mathrm{SN}$; (hsa) human cystatin SA; (bcc) bovine colostrum cystatin; (pac) African puff adder venom cystatin; (hk1, hk2 and hk3) three human kininogen segments; (bk1, bk2 and bk3) three bovine kininogen segments; (rk1, rk2 and rk3) three rat kininogen segments; (rk11, rk12, rk13) three rat T-kininogen 1 segments; (rt21, rt22, rt23) three rat T-kininogen 2 segments.

proteinases. Domain 2 was an inhibitor of calpain, papain and cathepsin $\mathrm{L}$, whereas domain 3 inhibited only papain and cathepsin L (reviewed in 8 and 9). The sequences of the three families of the cystatin superfamily are aligned in Fig. 1, according to the chicken cystatin numering system. The presented alignment is based on the known tertiary structure of human stefin $B$. the sequences are most highly conserved between residues 53-57 (QVVAG region) in the stefins and in the second and the third domain of the kininogens.

III. STRUCTURE OF CYSTATINS AND THEIR INTERACTION WITH CYSTEINE PROTEINASES

The X-ray crystal structure of chicken cystatin showed that the conserved QVVAG region is located in a $z$-hairpin loop, flanked on one side by the amino terminal segment and on the other side by a second hairpin loop (Pro103 - Trp104) forming a hydrophobic wedge-shaped "edge" which is highly complementary to the active site of cleft papain as shown by docking experiments (13). The proposed "trunk model" was verified by the crystallized complex of human stefin B and papain (12). The obtained data clearly show that the inhibition by the cystatins is fundamentally different to that observed for the serine proteinase inhibitors.

\section{ACKNOWLEDGEMENT}

This work was supported by the research grants from the Slovene Ministry for Science and Technology (Grant C1-0515-106). 
REFERENCES

(1) Bond, J. S., and Butler, P. E. (1987): Intracellular Proteases. Ann. Rev. Biochem., 56, 333 - 364.

(2) Katunuma, N. (1989): Possible regulatory mechanisms of intracellular protein catabolism through lysosome, in Intracellular Proteolysis, ed. by Katunuma, N. and Kominami, e., Japan Scient. Soc. Press, Tokyo, pp. 3 $-23$.

(3) Turk, V. (1986): Cysteine Proteinases and their Inhibitors, Walter de Gruyter, Berlin.

(4) Ritonja, A., Popovič, T., Turk, V., Wiedenmann, K., and Machleidt, W. (1985): Amino acid sequence of human liver cathepsin B. FEBS Lett., 181, 169 - 172 .

(5) Ritonja, A., Popovič, T., Kotnik, M., Machleidt, W., and Turk, V. (1988): Amino acid sequences of the human kidney cathepsin $\mathrm{H}$ and L. FEBS Lett., $228,341-345$.

(6) Ritonja, A., Čolić, A., Dolenc, I., Ogrinc, T., Podobnik, M., and Turk, V. (1991): The complete amino acid sequence of bovine cathepsin $\mathrm{S}$ and a partial sequence of bovine cathepsin L. FEBS Lett., 283, 329 - 331.

(7) Musil, D., Zučić, D., Turk, D., Engh, R. A., Mayr, I., Huber, R., Popovič, T., Turk, V., Towatari, I., Katunuma, N., and Bode, W. (1991): The refined $2.15 \AA$ X-ray crystal structure of human liver cathepsin B - the structural basis for its specificity. EMBO J., 10, 2321 - 2330.

(8) Barrett, A. J., Rawlings, N. D., Davies, M. E., Machleidt, W., Salvesen, G., and Turk, V. (1986): Cysteine proteinase inhibitors of the cystatin superfamily, in Proteinase Inhibitors, ed. by Barrett, A. J., and Salvesen, G., Elsevier, Amsterdam, pp 515 - 569.

(9) Turk, V., and Bode, W. (1991): The cystatins - protein inhibitors of cysteine proteinases. FEBS Lett., 285, 213 - 219.

(10) Barrett, A. J., Fritz, H., Grubb, A., Isemura, S., Jarvinen, M., Katunuma, N., Machleidt, W., Müller-Esterl, W., Sasaki, M., and Turk, V. (1986): Nomenclature and classification of the proteins homologous with the cysteine proteinase inhibitor chicken cystatin. Biochem. J., 236, 311 312.

(11) Ritonja, A., Kopitar, M., Jerala, R., and Turk, V. (1989): Primary structure of a new cysteine proteinase inhibitor from pig leucocytes. FEBS Lett., 285, 213 - 219.

(12) Stubbs, M. T., Laber, B., Bode, W., Huber, R., Jerala, R., Lenarčič, B., and Turk, V. (1990): The refined $2.4 \AA \mathrm{X}$-ray crystal structure of recombinant human stefin $B$ in complex with the cysteine inhibitor interaction. EMBO J., 6, 1939 - 1947. 
(13) Bode, W., Engh, R., Musil, Dj., Thiele, U., Huber, R., Karshikov, A., Brzin, J., Kos, J., and Turk, V. (1988): The 2.0 А X-ray crystal structure ofchicken egg white cystatin and its possible mode of interaction with cysteine proteinases. EMBO J., 7, 2593 - 2599. 